\title{
Uluslararası Ortak Girişimlerin Başarısında Kültürel Uyumun Etkisinin İncelenmesi
}

\author{
Beliz ÖZORHON ${ }^{1}$ \\ Hasan ALTUN ${ }^{2}$
}

\section{ÖZ}

Uluslararası ortak girişimler (UOG) stratejik bir alternatif olarak küresel rekabette büyük bir önem taşımaktadır. Farklı ülkelerden ortakların kurduğu girişimlerde, kültürel farklılıklar daha düşük performansa neden olabilmektedir. Bu çalışmanın başlıca amacı ulusal ve kurumsal kültür açısından ortakların uyumunun UOG performansı üzerindeki etkisini araştırmaktır. Bu kapsamda, Türkiye Müteahhitler Birliği (TMB) üyesi olan orta ve büyük ölçekli yüklenicilerin katılımıyla bir anket çalışması yapılmıştır. Elde edilen toplam 68 projeye ait veri regresyon ve korelasyon analizi kullanılarak incelenmiştir. Türk firmalarının yabancı ortakları ile aralarındaki kurumsal ve ulusal kültür uyumu hesaplanmıştır. Kurumsal kültürün ulusal kültüre nazaran performansı etkilemekte daha baskın olduğu gözlemlenmiştir.

Anahtar Kelimeler: Uluslararası inşaat, ortak girişimler, kültürel uyum, performans.

\section{ABSTRACT \\ Investigation of the Effect of Cultural Adaptation on International Joint Venture Performance}

International joint ventures (IJVs) have a great importance as a strategic alternative in global competition. Cultural differences between partners from different countries may cause lower performance levels in such ventures. The major objective of this study is to investigate the influence of national and organizational culture adaptation of partners on the IJV performance. In this respect, a questionnaire survey was administered to medium to large scale contractors, thgat are members of the Turkish Contractors Association (TCA). A total of 68 project data was studied using regression and correlation analysis. Organizational and national culture adaptation between Turkish firms and their foreign partners was calculated. It is observed that compared to the national culture, organizational culture has a more significant effect on the IJV performance.

Keywords: International construction; joint ventures; cultural issues; performance.

\footnotetext{
Not: Bu yaz1

- Yayın Kurulu'na 07.04.2015 günü ulaşmıştır.

- 30 Haziran 2017 gününe kadar tartışmaya açıktır.

1 Boğaziçi Üniversitesi, İnşaat Mühendisliği Bölümü, Istanbul - beliz.ozorhon@boun.edu.tr

2 Boğaziçi Üniversitesi, İnşaat Mühendisliği Bölümü, Istanbul - hasan.altun@boun.edu.tr
} 
Uluslararası Ortak Girişimlerin Başarısında Kültürel Uyumun Etkisinin İncelenmesi

\section{GíRiş}

Şirketler için stratejik işbirlikleri yoluyla rekabet avantajı yaratma kavramı 1980'lerin sonlarından itibaren yaygın bir şekilde tartışılmaya başlanmıştır [1]. Son yirmi yılda firmaların küresel açıdan birbirine daha bağımlı olma çabalarının bir sonucu olarak uluslararası ortak girişimlerin (UOG) sayısında büyük bir artış olmuştur. Özel bir stratejik işbirliği türü olan bu girişimler, katılımcı firmalara birbirinden farklı yeterliklerini ve tamamlayıcı kaynaklarını birleştirmek için olanak sunmaktadır. En az iki firmanın özkaynak ve kaynaklarını yarı özerk ve yasal olarak ayrı bir varlıkta birleştirmesi ile ortak girişim (OG) oluşmaktadır [2].

Geçtiğimiz on yılda uluslararası iş dünyasında görülen en büyük değişikliklerden biri olan artan UOG faaliyetleri, çok uluslu şirketler için sektöre giriş amacıyla sık başvurulan bir yöntem olmuştur. $\mathrm{Bu}$ tür işbirliğine dayalı faaliyetler gelişen ülkelerde yerel ortaklar, özellikle de endüstri grupları için iş stratejilerinin ayrılmaz bir parçası haline gelmiştir. UOG'lerin sağladığı yararlara rağmen başarısızlık oranları da yüksek olmuştur [3] çünkü UOG'ler yüksek istikrarsızlı ve zayıf performanstan olumsuz bir şekilde etkilenmektedirler [4].

Hem imalat sektöründe hem inşaat sektöründe önemli bir unsur olan OG'ler için başarı faktörleri de yaygın araştırma konuları arasında yer almaktadır. Robson ve diğerlerinin [5] çalışmasında UOG performansını etkileyen faktörler 10 tane iç etki ve 2 tane diş etki olmak üzere toplamda 12 gruba ayrılmıştır. Bunlar sırasıyla ortaklar arası özellikler, ortaklar arası uyum, girişimin demografisi, sözleşme bileşenleri, kontrol ve denetleme, projeye özgü ilişkisel durumlar, kurumsal öğrenme, Ar-Ge ve teknoloji, pazarlama, insan kaynakları, sektörel özellikler ve düzenleyici çevre olarak gözlemlenmiştir. OG'ler yap-işlet-devret, yap-sahiplen-işlet, yap- sahiplen-işlet-devret modeli ile projeler üstlenmek üzere konsorsiyum oluşturulan inşaat sektöründe yaygın olmasına rağmen, UOG'ler üzerine olan güncel çalışmalar çoğunlukla imalat sanayi üzerinde yoğunlaşmaktadır. İnşaat sektöründe UOG'lerin riskleri konusunda yürütülen birkaç çalışma $[6,7]$ ve UOG'lerin performansını etkileyen faktörlerin belirlenmesi üzerine yapılmış çalışmalar [8,9] dışında inşaat sektöründe UOG teorileri görgül olarak çok az araştırılmıştır. Ayrıca, Chan ve Tse [10] tarafından yürütülen bir çalışmada da uluslararası inşaat projelerinin yönetimini etkileyen önemli konulardan biri olan kültür konusunun büyük ölçekte araştırılmasının gerekliliği belirtilmiştir.

UOG performansının ölçülmesi karmaşık ve çok boyutlu bir olgu olduğundan dolayı araştırmacılar için her zaman çeşitli zorluklar bulunmaktadır. UOG performansının değerlendirilmesinde genellikle üç ana zorlukla karşılaşılmışıı. Bunlardan ilki öncelikle UOG ortakları, girişim ve projeden hangisinin performansının ölçülmesi gerektiğine dair karar verme zorluğu olarak ortaya çıkmıştır. İkinci zorluk performans göstergesi olarak nesnel veya öznel ölçütler kullanma kararından oluşmaktadır. Üçüncü zorluk tam ve geçerli bir performans göstergeleri listesinin oluşturulması ve bu göstergeler arasındaki ilişkilerin tanımlanmasının zorluğu olmuştur. UOG performansını etkileyen birçok potansiyel faktör literatürde sunulmaktadır $[11,12,13]$. İnşaat sektöründe, performans ölçümü ve yönetimine dair çalışmalar $[14,15]$ proje veya şirket performansının ölçülmesi gerektiğine dair bir çerçeve çizilmesinin gerekliliğini vurgulamaktadır. İnşaat sektöründe oluşturulan UOG'ler için farklı performans ölçütleri geliştiren çalışmalar $[8,16]$ ve bu UOG'lerin performansını etkileyen faktörleri belirleyen çalışmalar $[11,17]$ da bulunmaktadır ancak bu konuda henüz 
tam bir ölçüt ve fikir birliği oluşmamıştır. Özorhon ve diğerlerinin [11] çalışmasında, UOG performansını etkileyen faktörler 5 ana grupta ele alınarak ortaklar arası uyum, ortakların ikili ilişkileri, ortak girişimin yapısal özellikleri, evsahibi ülke ile ilgili faktörler ve UOG'nin yaptığı proje ile ilgili özellikler şeklinde sınıflandırılmıştır. Ortaklar arası uyum diğer bütün faktörleri etkilediğinden bu çalışmada ortaklar arası uyum detaylı olarak ilerleyen bölümlerde anlatılmıştır.

Kültürel mesafe konusu uluslararası iş literatüründe kapsamlı olarak incelenmiştir [18, 19, 20]. "Kültür" terimini her yönüyle kapsayan tek bir tanım ortaya çıkmamıştır. Bazı araştırmacılar tarafindan "bir grup, kurum veya milletin üyeleri arasındaki ortak deneyim, anlayış ve anlamlar kümesi” olarak tanımlanmaktadır [21]. Kültür, toplu grupların uluslararası iş firsatlarına yaklaşma, onları değerlendirme ve müzakere etme şekillerini etkileyen oturmuş davranışsal bir etkidir. Farklı kültürlerin farklı yönetim modelleri ve kurumların yapısına dair farklı görüşleri bulunmaktadır [22]. Kültür, yabancı pazar çekiciliği, genişleme modelleri, pazarlama ve perakende stratejilerinin uyarlanma derecesi, sektöre giriş koşulları ve kurumsal performansı açıklayan kilit bir faktör olarak tanımlanmıştır [23].

$\mathrm{Bu}$ çalışma ortakların ulusal ve kurumsal kültür açısından uyumunun UOG performansı üzerindeki etkisini incelemektedir. UOG performansı 'genel memnuniyet' olarak tanımlanmış ve bu araştırmada ortaklardan birinin algısı üzerinden ölçülen öznel bir gösterge olarak UOG başarısı şeklinde sunulmuştur. Ortakların kültürel farklılıklarını ölçmek için Hofstede'nin [24, 25] ulusal ve kurumsal kültür boyutları kullanılarak bir anket hazırlanıp yabancı ortaklarla UOG oluşturmuş Türk inşaat şirketlerine gönderilmiş̧ir. Ankete gelen yanıtlar çerçevesinde, regresyon analizi yapılmış ve elde edilen bulgular 1şığında ulusal kültür ve kurumsal kültür ile UOG performansı arasındaki iliş̧i incelenmiştir.

\section{ULUSLARARASI ORTAK GIIRIŞIM PERFORMANSI}

Dünyada ekonomilerin küreselleşmesinin devam etmesi ile birlikte OG'ler pek çok şirketin uluslararası stratejisinin önemli bir öğesi haline gelmiştir. Bilinen en eski organizasyon yapılarından olan OG'ler Antik Mısır ve Mezopotamya'nın tüccarları tarafından denizaşırı ticari işlemler yapmak için bir araç olarak kullanılmıştır. Özellikle 1970'lerden bu yana OG'ye başvurma sayısında artış gözlemlenmektedir. Fakat OG'lerin çok uluslu yapısı bu tür yapılanmalarda çeşitli problemlerin ortaya çıkmasına neden olmaktadır [26]. OG'ler yasal olarak birbirinden ayrı olmalarına rağmen, karar alma faaliyetlerine aktif olarak katılan iki ya da daha fazla kurumun bir araya gelmesiyle oluşan yapılanmalardır [2]. Ortaklardan en az biri OG'nin faaliyet ülkesinin dışında konumlanmışsa veya OG'nin faaliyetlerinin önemli bir kısmı birden fazla ülkede gerçekleşiyorsa bu yapı UOG olarak kabul edilmektedir.

Genellikle farklı yönetim sistemleri, felsefeler, değerler ve tutumları olan iki veya daha fazla ortak kuruluşun varlığı işbirliğinin yanı sıra rekabeti de içinde barındırmaktadır. Dolayısıyla, UOG yönetimi ve başarısı için iyi bir performans elde etmek zorlaşmaktadır [27, 28, 29]. Özorhon ve diğerlerinin [11] çalışmasında UOG performansını etkileyen faktörler detaylı bir şekilde incelenmiştir. Bu çalışma kapsamında, ortakların ikili ilişkilerini etkileyen faktörler ortakların birbirine ve ortak girişime olan bağlılıkları (iyi 


\section{Uluslararası Ortak Girișimlerin Başarısında Kültürel Uyumun Etkisinin İncelenmesi}

niyetleri, vaatleri), ortaklar arası iletişimin etkinliği, şirketlerin uyuşmazlıklarda ortak çözüm üretebilmesi, ortakların birbirine güven duyması, ortakların geçmişte işbirliklerinin bulunması ve stratejik kararların verilmesinde ortakların işbirliği içinde bulunması şeklinde belirlenmiştir. UOG'nin yapısal özellikleri, UOG’nin stratejik (üst düzey yönetim), operasyonel (günlük işleyiş) ve organizasyonel kontrolünün etkinliği, UOG'deki ortaklık oranı ve ortaklar arasında yapılan sözleşmenin eksiksiz/tatmin edici olması şeklinde sunulmuştur. Evsahibi ülke ile ilgili faktörler de, evsahibi ülkenin politik sisteminin istikrarlı olması, evsahibi ülkenin ekonomik koşullarının iyi olması, evsahibi ülkedeki yasal sistemin güçlü olması, evsahibi ülkeyle ilişkilerin güçlü olması, ortak girişimin evsahibi ülkenin diline olan yakınlı̆̆ı, ortak girişimin evsahibi ülkedeki ticari faaliyetlere olan yakınlığ 1 , ortak girişimin evsahibi ülkenin siyasi ve yasal sistemine olan yakınlı̆̆ girişimin evsahibi ülkenin ekonomik yapısına olan yakınlığı, ortak girişimin evsahibi ülkenin sektörel yapısına olan yakınlığı ve ortak girişimin evsahibi ülkenin milli kültürüne olan yakınlığı olmak üzere 10 başlık altında sınıflandırılmıştır. UOG’nin yaptığı proje ile ilgili özellikler ise, ödemelerin zamanında ve eksiksiz yapılması, işverenin esnek (hoşgörülü) olması, projede yer alan diğer firmalarla ilişkilerin iyi olması, projede yer alan diğer firmaların yeterliliği/performansı, projenin eksiksiz tanımlanmış olması, kaynakların (insan, ekipman, malzeme, vb.) yeterliliği, projenin teknik açıdan karmaşık ya da zor olmaması, dış faktörlerin (hava koşulları, mücbir sebepler, vb.) etkilerinin fazla olmaması, tasarımın doğru ve eksiksiz olması, sözleşmenin eksiksiz/tam olması, proje gereklerinin (kalite, çevre, işçi sağlı̆̆ 1 ve iş güvenliği, vb.) çok katı olmaması, süre ile ilgili cezai şartların çok ağır olmaması ve proje yönetiminin (planlama, koordinasyon, kontrol, izleme) sorunsuz işlemesi olarak toplamda 13 başlık altında incelenmiştir.

Abdul-Rahman ve diğerleri [17] yaptıkları Bahreyn Formula-1 Pisti inşaat projesi vaka analizinde, UOG'lerin başarısının, gelişmiş teknik ve mühendislik uzmanlığı, kararlı (bağlı) bir ortak seçimi, yönetim uzmanlığı, yaratıcı ve sürdürülebilir iyi bir çalışma ortamı, uygun risk yönetimi, güvenilir bir uluslararası malzeme tedarik zinciri, verimli bir proje planlama ve izleme sistemi gibi etmenlere bağlı olduğunu belirtmişlerdir. Ayrıca, karakteristikleri ve problemleri sebebiyle de UOG projelerinin başarısını en çok etkileyen faktörün yönetim uzmanlığı olduğunu belirtmişlerdir. Larimo ve Nyugen [12], Fin firmaların, Baltık ülkelerinde kurdukları UOG'lerin performanslarını ve yatırım stratejilerini analiz ettikleri araştırmasında, UOG performanslarındaki farklılıkların ortakların hedefleri, rekabet stratejileri, ortaklığa giriş biçimleri, girişimin yaşı, kontrol stratejileri, güven seviyeleri ve ortaklar arasındaki bağlılık seviyelerinden kaynaklandığını ortaya çıkarmıştır.

Özorhon ve diğerleri [16] UOG'lerin performansını etkileyen ana faktörlerden biri olan ortaklar arası uyumu, stratejik uyum, kurumsal uyum ve kültürel uyum olarak üç başlık altında ele almıştır. Ortaklar arası uyumun bileşenleri bir sonraki bölümde detaylarıyla anlatılmaktadır.

Ortaklar arası uyum, ortak olan firmaların anlaşabilme ve ortak girişimden beklenen sinerjiyi yakalayabilme oranlarını belirlemektedir [30]. Ortakların uyumu konusu ve UOG'de ortak seçimi literatürde kapsamlı şekilde ele alınmıştır. Örneğin, Geringer [2] UOG'de ortak seçimi aşamasında hem görevsel özelliklerde (örneğin kaynaklar ve beceriler) hem de ortakla ilgili özelliklerde (örneğin boyut, hedefler ve faaliyet politikaları) uyuma bakılması gerektiğini savunmaktadır. Önceki araştırmalar "ortaklar arası uyum" ve UOG performansı arasında bir bağlantıya işaret etmektedir. Ancak, "uyum" stratejik simetri 
[31], firmalar arası çeşitlilik [32], ortak özelliklerinde eşleşme [2] veya ortaklar arası uygunluk/tamamlayıcılık [33] gibi farklı kavramlar aracıllğıyla tanımlanmıştır. Bu olgunun kritik özelliklerinin iyi belirlenmediği veya o özelliklere dair uygun önlemler önerilmediği sürece ortaklar arası uyum çalışmaları sınırlı düzeyde kalmaktadır. Bu da ortaklar arası uyumun, çeşitli faktörlerin birleşiminden oluşan çok boyutlu ve karmaşık bir kavram olmasından kaynaklanmaktadır. Önceki araştırmalara göre ortaklar arası uyumu etkileyen faktörler genellikle stratejik uyum, kaynak uyumu, operasyonel uyum, kurumsal uyum ve kültürel uyum olarak belirlenmiştir $[30,34]$. Ancak her bir çalışmada yapılan varsayıma bağlı olarak bu boyutlar arası bir kesişim bulunmaktadır. Bu çalışmada ortaklar arası uyum stratejik, kurumsal ve kültürel uyum olmak üzere üç ana başlıkta incelenmektedir.

\subsection{Stratejik Uyum}

Ortak olan şirketlerin stratejik yönelimi UOG'nin faaliyetlerinde başarı için büyük önem taşımaktadır. Stratejik hedefler ve davranışlar, işbirliği kültürü, yönetim felsefesi, yenilikçilik ve uzun vadeli yönelim konularında ortaklar arası uyum, taraflar arasında karşılıklı güven, bağlılık ve işbirliğini etkilemektedir [32]. Stratejik uyum, UOG ortakları arasında hedef örtüşmesi, evsahibi ülkedeki deneyim, benzer projelerde deneyim, yönetimsel becerilerin yeterliliği, teknik beceriler, insan kaynağı ve müşteriyle ilişkinin kalitesinden oluşmaktadır [11].

i. Ortaklar arasında hedef örtüşmesi UOG başarısında birincil faktör olmuştur [35]. Ortaklar arasında doğabilecek fikir ayrılıkları UOG performansını olumsuz yönde etkileyebilmektedir [36]. Bu hususta, Hennart ve diğerleri [37] hedefler konusunda ortaklar arasındaki farklılığın UOG’nin dağılma riskini arttırdığını söylemektedir.

ii. Evsahibi ülkedeki deneyim açısından ortaklar arası tamamlayıcılık önemli bir stratejik varlıktır. Bu süreçte yabancı firmalar UOG'nin lokasyonunun siyasi, sosyal, ekonomik ve kültürel yönleri hakkında genel ve yerel işletme uygulamaları ve yerel ağlar konusunda özel bilgiler toplamaktadırlar [38]. Edinilen bu bilgi ortaklar arasında güven ve işbirliğini teşvik etmektedir. Luo [39] da bu etkiyi destekleyen bir çalışma yapmıştır.

iii. Proje deneyimi açısından ortakların birbirini tamamlaması UOG'nin başarısı için kritik unsurlardan biridir. Ortakların yeni bilgi ve becerileri edinme, öğrenme, işleme, özümseme, entegre etme, kullanma ve değerlendirme başarısı bunların var olan becerilerle ne derece alakalı olduğuna göre değişmektedir [39]. Günhan ve Arditi'nin [40] çalışmasında da uluslararası pazarlarda faaliyet gösteren bir şirket için özel bir uzmanlık alanına sahip olmanın önemli bir avantaj olduğu vurgulanmaktadır.

iv. Ortakların yönetim becerileri, teknik beceri ve insan kaynağı arasındaki uyum bir firmanın bir projeyi tamamlaması açısından önemlidir. Uyumlu yönetim becerileri ortakların sadece UOG'yi verimli şekilde yönetmesini değil diğer proje katılımcılarıyla iyi ilişkiler yürütmelerini de sağlamaktadır. Uyumlu teknik beceriler maliyet, zaman ve kalite sorunlarına yol açabilecek olası proje risklerini sorunsuz şekilde azaltmak adına büyük önem taşımaktadır. Son olarak, insan kaynağı ortakların kültür ve yönetim tarzlarının karışımını yansıtmakta ve bu şekilde UOG'nin iş tasarımı, işe alma, çalışan seçme, oryantasyon ve eğitim, performans değerlendirme, tazminat ve çalışan yardımları, kariyer gelişimi ve iş gücü yönetimi ilişkilerini etkilemektedir [34]. 
Uluslararası Ortak Girişimlerin Başarısında Kültürel Uyumun Etkisinin İncelenmesi

v. Ortakların işveren ile iyi ilişkileri de stratejik uyumun iyi bir göstergesidir. İşveren memnuniyeti performansı belirlemede önemli bir unsur olduğundan, güçlü müssteri ilişkileri, işveren ile ilişkili sorunları çözmede oldukça faydalıdır.

\subsection{Kurumsal Uyum}

Kurumsal uyum, ortakların finansal yetenekleri, şirket büyüklüğü, yönetim sistemleri ve ulusal ve uluslararası iş yükü arasındaki uygunluk/tamamlayıcılıktan oluşmaktadır.

i. Ortak firmaların finansal yeterlikleri kritik öneme sahiptir. Çünkü bir ortağın kâr payı, sermaye katkısı yapabilme, finansal sözlerini yerine getirebilme ve operasyona finansal kaynak aktarma becerisini doğrudan etkilemektedir.

ii. Ortak firmaların büyüklüğü UOG performansının önemli bir belirleyicisi olmuştur [37]. $\mathrm{Bu}$ konuda yapılan çalışmalar, ortakların büyüklüğü konusunda asimetri olmasının UOG’nin istikrarını olumsuz etkilediğini göstermektedir [2, 28, 31]. Nitekim, Geringer [2] ve Killing [28] küçük ölçekli bir firma ile büyük ölçekli bir firmanın stratejik misyon, kurumsal kültür ve bürokrasi seviyeleri açısından eşleştirilmesinde uyumsuzlukların ortaya çıkacağını savunmuşlardır. Park ve Ungson [19] ölçek farkının süre ve UOG'lerin performansını etkilemediğini belirtmişlerdir.

iii. Ortakların yönetim sistemleri arasındaki benzerlik UOG performansının bir diğer önemli belirleyici unsurlarından biri olmuştur [28, 41]. Ortakların yönetim biçimleri arasındaki farklılıklar, ortaklar arası çıkar çatışmalarına neden olabilmekte ve bu tür çatışmaların çözülmemesi sonucunda OG performansı olumsuz etkilenebilmektedir [42].

iv. Ortakların ulusal ve uluslararası iş yükü UOG'ye ayırdıkları çaba ve zamanı etkileyebilmektedir. Uluslararası alanda etkin olan bir ortak, UOG'ye olan bağlılığını azaltma eğiliminde olabilmekte [41] ve bu da UOG performansını etkileyebilmektedir.

\subsection{Kültürel Uyum}

Cartwright ve Cooper [43] kültürü bireyleri bağlayan ve kurumsal uyum sağlayan bir 'sosyal tutkal' olarak tanımlamış ve "kurumlar arasındaki kültürel uyum derecesi birleşmenin başarısıyla doğrudan ilişkilidir" diyerek külttürün UOG performansı üzerindeki etkisini vurgulamıştır. Doğası gereği uluslararası stratejik işbirlikleri ulusal kültürlerin farkl1lıklarından etkilenmektedirler [19, 44]. Kültürel uyumun UOG başarısı üzerindeki etkilerine dair çalışmalar bir sonraki bölümde detaylı bir şekilde sunulmaktadır.

\subsubsection{Ulusal Kültür - UOG Başarısı Arasındaki İlișki}

Hofstede ve Hofstede [22] belirli bir ülkede yaşayan bireylerin benzer değer eğilimleri olduğunu ve bu değerleri çalıştıkları şirketlerin bünyesine de taşıdıklarını göstermişlerdir. $\mathrm{Bu}$ nedenle, bir firmanın değerlerinin büyük oranda ulusal kültürün bir yansıması olduğu ortaya çıkmaktadır. Farklı ülkelerde bulunan UOG ortaklarında farklı değerlere sahip olma eğilimi olması beklenmektedir. Bu değer farklılıkları ise farklı ülkelerden gelen UOG 
ortaklarının amaç, çözüm ve uyuşmazlıklarının ortadan kaldırılmasında zorluklar çıkaracaktır.

Önceki çalışmalar kültürel farklılıkların UOG performansı üzerinde etkili olduğunu saptamıştır [45]. Bazı araştırmacılar ise ulusal kültürdeki farklılıkların uyuşmazlıklara ve engellere neden olduğunu savunmuştur [46]. Nielsen [47], kültürel mesafenin birbiriyle olumsuz ilişkili dört etkisini tanımlamaktadır. Bunlar sırasıyla: kültürel mesafe, bilgi alışverişi ve örgütler arası öğrenmeyi engelleyecek iletişim sorunlarına yol açabilmektedir; yanlış anlaşmalardan ortaya çıkabilecek yönetimsel uyuşmazlıkların getirdiği ilave maliyetler oluşabilmektedir; uyuşmazlıkların çözüm yöntemine farklı yaklaşımlar, operasyon üzerinde ters etkiler yaratabilmektedir ve bazı ortak yetkinliklerinin uygulanabilirliğine işbirliğinin potansiyel faydalarını azaltabilecek şekilde zarar verebilmektedir $[19,32]$.

Parkhe [32], algı ve olayların yorumlanmasında kültürel farklılıkların ulusal yönü nedeniyle UOG'lerde istikrarsızlıklara neden olduğunu savunmuştur. Makino ve Beamish [3] ise benzer ulusal kültürlere sahip ortakları olan UOG'lerin süreklilik sağlama oranlarının ve performans seviyelerinin farklı ulusal kültürlere sahip ortakları olan UOG'lerden daha yüksek olduğunu vurgulamıştır. Örneğin, Barkema ve Vermeulen [44], ulusal kültürler arasındaki mesafe ile UOG'nin sürdürebilirliği arasında olumlu bir ilişki bulmuştur. Başka bir araştırmada, Park ve Ungson [19] UOG ortakları arasındaki farklılık arttıkça UOG’nin istikrarının azalacağını öne sürmüşler, fakat araştırma sonucunda farklı bir sonuca ulaşmışlardır. Fey ve Beamish [48] UOG ortaklarının ulusal kültür farklılıkların UOG’nin performansı üzerinde etkisi olmadığını savunmuşlardır. Tihanyi ve diğerlerinin [49] çalışması ulusal kültürel farklar ve UOG performansı arasında istatistikî olarak yeterli veriye sahip olmadığından UOG'ler hakkında detaylı bilgi verme konusunda başarısız olmuştur.

\subsubsection{Kurumsal Kültür - UOG Başarısı Arasındaki İlişki}

Hofstede ve Hofstede [22] kurumsal kültürü "bir grubun üyelerini bir diğerinden belirgin bir şekilde ayıran kolektif zihinsel program" olarak tanımlamıştır. Schein [50] ise "çalışanların dışsal adaptasyon ve içsel entegrasyon ile çözümlenmiş problemleri referans alarak; çevre, insan doğası, sosyal ilişkiler ve gerçekliklere dair paylaştıkları temel varsayımlardır" diyerek farklı bir bakış açısı getirmiştir.

Kurumlar, daha büyük toplumların içinde var olmaları nedeniyle uluslararası işlerdeki kültürel farklılıklar üzerine yapılan araştırmalar hem ulusal kültür hem de kurumsal kültür yönünden incelenmelidir. Bazı araştırmacılar [51] ulusal kültürün kurumsal kültürü kapsadığını savunmasına rağmen, çoğu araştırmacı ulusal ve kurumsal kültürü ayrı yapılar olarak değerlendirmektedir $[52,53]$.

Farklı kurumsal kültüre sahip ortaklar, ortak fayda sağlamak ve ortak yönetimsel beceriler edinmek için büyük çaba sarf etmektedirler. Bu da benzer kurumsal kültürleri olan kurumlara göre daha yüksek maliyet ve güvensizliğe yol açabilmektedir [19]. Pothukuchi ve diğerleri [53] UOG'lerin performansları üzerindeki etkinin ulusal kültür farkından çok kurumsal kültür farkından kaynaklandığını bulmuştur. Başka bir çalışmada ise Brown ve 
Uluslararası Ortak Girişimlerin Başarısında Kültürel Uyumun Etkisinin İncelenmesi

diğerleri [54] ortakların kurumsal kültürlerindeki uyumsuzluğun UOG'lerin performansında belirgin fark yaratabileceği sonucuna varmıştır.

\subsubsection{Kültürel Uyumun UOG Başarısı Üzerindeki Etkisi}

Bir UOG’yi idare etme ulusal ve kurumsal kültür farkl1lıklarını yönetmeyi de gerektirmektedir. Bir firmanın kurumsal kültürünün zaman zaman değişiklik göstermesi sebebiyle, UOG'nin ortakları arasındaki kurumsal kültür farklılıkları çoğunlukla giderilebilmektedir. Ancak ulusal kültür bir firmanın uygulamalarının yanı sıra firma bireylerinin davranışlarında da kökleşmiş bir olgu olduğu için ulusal kültür farklılıkları UOG ortaklarının tamamlayıcılıklarını büyük oranda etkileyebilmektedir.

\section{ARAŞTIRMA YÖNTEMI}

Bu çalıșma kapsamında, UOG ortakları arasındaki hem ulusal hem kurumsal kültürel farkları ve ölçmek üzere bir anket hazırlanmıştır. Bu araştırmanın temel amacı kültürel farklılıkların UOG performansı ile ilişkisini ortaya çıkarmaktır. Veri toplama UOG'lerin Türk ortakları ile yüz yüze görüsşmeler ve e-posta aracıllğıyla yapılmıştır. Anket verilerine göre, projelerin yaklaşık yarısı 18 farklı ülkede (ABD, Afganistan, Bulgaristan, Ürdün, Rusya, Irak, Hindistan, vs) yapılmaktayken kalan kısmı da Türkiye'de gerçekleştirilmiştir. Orta ve büyük ölçekli şirketlerin küçük ölçekli şirketlere göre UOG'ler oluşturma ihtimalinin daha fazla olacağı göz önünde bulundurularak, hedef örneklem olarak Türkiye Müteahhitler Birliği (TMB) üyeleri belirlenmiştir. Ankete katılan firmaların inşaat sektöründe ortalama 40 yıldır faaliyet gösterdikleri ve hem ulusal hem de uluslararası piyasada genel müteahhitlik ve altyapı inşaat işleri konusunda deneyimi oldukları gözlemlenmiştir. Çalışma kapsamında tespit edilen 110 adet UOG projesinden 68 tanesi ile ilgili veri toplanabilmiştir. Bu verilerin 48'i yüz yüze, 20'si ise e-posta yoluyla edinilmiş̧tir. Böylelikle, hedef popülasyonun yaklaşı olarak \%60'ını kapsayan bir çalışma gerçekleştirilmiştir. Katılımcı firmaların ulusal kültür ve kurumsal kültür uyumları ile UOG'nin genel başarısını UOG'nin temel özelliklerini dikkate alarak değerlendirmeleri (15 Likert ölçeği kullanarak) istenmiştir.

\subsection{Ulusal Kültür}

Özorhon ve diğerlerine [16] göre, ulusal kültürün ölçülmesine dair birçok yöntem ulusal kültürü güç mesafesi, belirsizlikten kaçınma, bireycilik-çoğulculuk, erillik-dişilik ve uzun vade yönelimi boyutları olarak tanımlamıştır. Hofstede ve Hofstede'nin [22], 50 ülkede ve 3 çok uluslu bölgede, 117 bin IBM çalışanını içeren araştırması ulusal kültürü çalışmalarının temelini oluşturmaktadır. Hofstede'nin ulusal kültür boyutları aşağıda sıralanmıştır:

1. Güç mesafesi: Toplumda bireyler arasında gelir dağılımında eşitsizlik olması ve güç dengesizliği olarak tanımlanmaktadır. Güç dengesizliğinin yüksek olduğu toplumlarda gelir dağılımında eşitsizlikler olduğu; güç dengesizliğinin düşük olduğu toplumlarda ise bireylere eşit firsatlar tanındığı görülmektedir. 
2. Bireycilik-çoğulculuk: Toplumda bireyci ya da kollektif bir yaklaşım olduğunu ifade etmektedir. Bireyciliğin hâkim olduğu toplumlarda kişisel hakların ön plana çıkarıldığı fakat toplumsal ilişkilerin zayıf olduğu; çoğulculuğun hâkim olduğu toplumlarda ise aile değerlerine önem verildiği, sorumlulukların paylaşıldığı ve kuvvetli ilişkilerin desteklendiği görülmektedir.

3. Erillik-dişilik: Toplumun geleneksel eril iş modelini ve başarısını ne oranda desteklediği veya desteklemediği konularını ele almaktadır. Erillik-dişilik değeri yüksek olduğunda atılganlık ve rasyonel-başarı modeli ortaya çıkmakta ve düşük erillik-dişilik değerleri olan ülkelerde, uysallık ve duygusallık eğilimleri modeli ön plana çıkmaktadır.

4. Belirsizlikten kaçınma: Toplum içindeki belirsizliğe karşı toplumun hoşgörü düzeyini incelemektedir. Belirsizlikten kaçınma değerinin yüksek olduğu durumlarda kurumsal istikrar için çatışma ve riskten kaçınma arzusunun olduğu görülmektedir. Düşük belirsizlikten kaçınma değerleri olan toplumlarda ise, risk ve çatışmanın benimsendiği ve değişikliklere karşı daha esnek bir yapının var olduğu görülmektedir.

5. Uzun vade yönelimi: Toplumun uzun vadeli taahhütleri geleneksel olarak ne derece benimsediği konularını incelemektedir. Yüksek değerler uzun vade yönelimini dolayısıyla da uzun vadeli taahhütlerin gerçekleştirilmesinin geleneksel olarak takdir edildiğini göstermektedir. Düşük değerler ise geleneksel olarak uzun vade yöneliminin toplum tarafından önemsenmediğini göstermektedir.

\subsection{Kurumsal Kültür}

Her kurumun kendi üyelerini diğerlerinden ayrıştıran kendi kültürü ve paylaştığ 1 bir sistemi bulunmaktadır [22]. Bu çalışmada UOG ortakları arasındaki benzerlikleri ölçmek için Hofstede ve diğerlerinin [52] önermiş olduğu kurumsal kültür boyutları ele alınmıştır. Hofstede ve diğerleri [52] kurum kültürünün soyut varsayımlar ve değerler yerine kurumsal uygulamalar ile daha doğru ölçülebileceğini savunmaktadır. Aşağıda çok sayıda kurumsal uygulamayı açıklayan altı bağımsız boyut tanımlanmıştır [55]:

1. Süreç/sonuç odaklllık: Belirli bir kurumsal kültürde işin nasıl yapıldığı veya işin sonucunda verilen önemi göstermektedir. Süreç odaklı kültür çalışanları belirsizliği önleme eğilimindeyken, sonuç odaklı kültür çalışanları ise belirsizliği meydan okuma olarak görmektedirler.

2. Çalışan/iş odaklllık: Belirli bir kurumsal kültürde işi kimin yaptığı veya işe verilen önemi göstermektedir. Çalışan odaklı kültürlerde, çalışanların da fikirlerine değer verilerek çalışanlara vakit ayrılmakta fakat iş odaklı kültürlerde, çalışanlara işin zamanında bitirilmesi adına yoğun baskı uygulanmaktadır.

3. Amatör/profesyonel yaklaşım: Belirli bir kurumsal kültürde çalışanların kendilerini işyerlerinde ne kadar rahat hissettiklerini göstermektedir. Amatör yaklaşıma sahip kültürlerde çalışanlar kendilerini evlerinde gibi hissetmektedirler. Ayrıca bu çalışanlar, kimliklerini kurumdan almakta ve birbirlerine güven duymaktadırlar. Fakat profesyonel yaklaşıma sahip kültürlerde, çalışanların iş ve ev hayatları kesin olarak ayrılarak ve çalışanlar yaptıkları iş ile tanımlanmaktadırlar. 
Uluslararası Ortak Girişimlerin Başarısında Kültürel Uyumun Etkisinin İncelenmesi

4. Açık/kapalı sistem anlayışı: Belirli bir kurumsal kültürde yeni çalışanlara gösterilen yakınlık ve hoşgörü düzeyini belirtmektedir. Kapalı sistem kültürü, yeni gelenlere kapalı ve gizli bir yapıdayken, açık sistem kültürü ise yeni gelenlere açık ve kapsayıcı olarak gözükmektedir.

5. Gevşek/sık kontrol: Belirli bir kurumsal kültürde iç yapılanmanın derecesi üzerinde durmaktadır. Gevşek kontrollü birimlerde, maliyetlerin düşünülmesi ve işlerin zamanında yapılması bir erdem sayılmazken, sıkı kontrollü birim çalışanlarında, maliyet bilinci ve işlerin zamanında yapılması oldukça önem taşımaktadır.

6. Kuralcı/faydacı yaklaşım: Belirli bir kurumsal kültürde sorunların belli kurallarla mı yoksa pratik yöntemlerle mi çözüldüğünü belirtmektedir. Kuralcı yaklaşıma sahip kültürlerde sonuçtan ziyade kurallara uymak önem taşımakta iken faydacı yaklaşıma sahip kültürlerde basit çözüm yollarıyla istenilen sonuçlara ulaşılabildiği görülmektedir.

\subsection{UOG Performansı}

Bir UOG'nin performansının değerlendirilmesinde öznel ya da nesnel göstergeler veya bunların birleşiminden meydana gelen çoklu göstergeler kullanılabilmektedir. UOG performansı için nesnel ölçütler olarak mali kriterler (karlılık, büyüme, maliyet durumu, vb ölçütler) ve stratejik ittifakın uzun ömürlü olması ile operasyonel ölçütler sıralanabilmektedir. Ancak şirketlerin performanslarını artırmak amacı ile yalnızca standart mali veya operasyonel hedefleri yerine getirmek için bir UOG'de yer almak yerine, kurumsal öğrenmeyi geliştirmek [56], stratejik pozisyonlarını geliştirmek [29, 57] veya yeni pazarlarda varlığını sürdürmek gibi ek motivasyonları benimseyebileceği gerçeği göz ardı edilmemelidir, zira UOG performansını ölçmek için mali ve operasyonel ölçümler yapma ile ilgili zorluklar, birçok araştırmacıyı öznel ölçümler yapmaya yöneltmektedir [28, 48].

Herhangi bir ortağın UOG genel performansından olan memnuniyeti UOG performansı ölçümü için en sık kullanılan öznel yaklaşımlardan biri olmuştur $[4,26,28,48]$. Katılımcıların algılarına dayalı öznel göstergelerin temel getirisi UOG'nin genel hedeflerinin (mali, kendini idame etmesi, genişleme hedefleri veya duruma göre herhangi farklı bir amaç) ne ölçüde gerçekleştirildiğine iliş̧kin bilgi sağlaması olmuştur. Girişim ortağının UOG'den duyduğu genel memnuniyet bu çalışmada öznel performans göstergesi olarak ele alınmaktadır.

\section{ARAŞTIRMA BULGULARI}

Kültürün UOG performansı üzerindeki etkisini araştırmak amacıyla, toplanan veri Minitab 16 ve MS Excel istatistiksel analiz programları kullanılarak incelenmiştir. Elde edilen tanımlayıcı istatistikler Çizelge 1'de gösterilmiştir.

Bu çalışmada, kültür bileşenleri olan ulusal kültür ile kurumsal kültür analiz edilmiş ve UOG başarısı da karşılaştırma için performans göstergesi olarak belirlenmiştir. Toplamda 25 farklı ülkeden 68 adet projeye ait veriler analiz edilmiş olup ortaklıkların ülkelere göre dağılımı Şekil 1'de gösterilmektedir. Gösterimi sadeleştirmek için ortaklık sayısı sadece bir 
adet olan ülkeler grafikte gösterilmemiştir. Ortaklıkların İngiltere, Almanya ve ABD ile daha sık oluşturulduğu tespit edilmiştir.

Çizelge 1. Tanımlayıcı İstatistikler

\begin{tabular}{cccc}
\hline & UOG Başarıs & $\begin{array}{c}\text { Ulusal Kültür } \\
\text { Uyumu }\end{array}$ & $\begin{array}{c}\text { Kurumsal } \\
\text { Kültür Uyumu }\end{array}$ \\
\cline { 2 - 4 } Ortalama & 3,5294 & 3,0984 & 3,3617 \\
Standart Hata & 0,1098 & 0,0674 & 0,0825 \\
Medyan & 4 & 3,0263 & 3,3747 \\
Kip & 4 & 3 & 3 \\
Standart Sapma & 0,9055 & 0,5559 & 0,6804 \\
Örnek Varyans & 0,8200 & 0,3090 & 0,4629 \\
Basıklık & $-0,1159$ & $-1,0490$ & $-0,1716$ \\
Çarpıklık & 0,2765 & 0,0457 & $-0,0522$ \\
Aralık & 4 & 1,9958 & 2,9437 \\
Minimum & 1 & 2,0667 & 1,7600 \\
Maksimum & 5 & 4,0625 & 4,7037 \\
Gözlem & 68 & 68 & 68 \\
Güven Aralığı (\%95) & 0,2192 & 0,1345 & 0,1647 \\
\hline
\end{tabular}

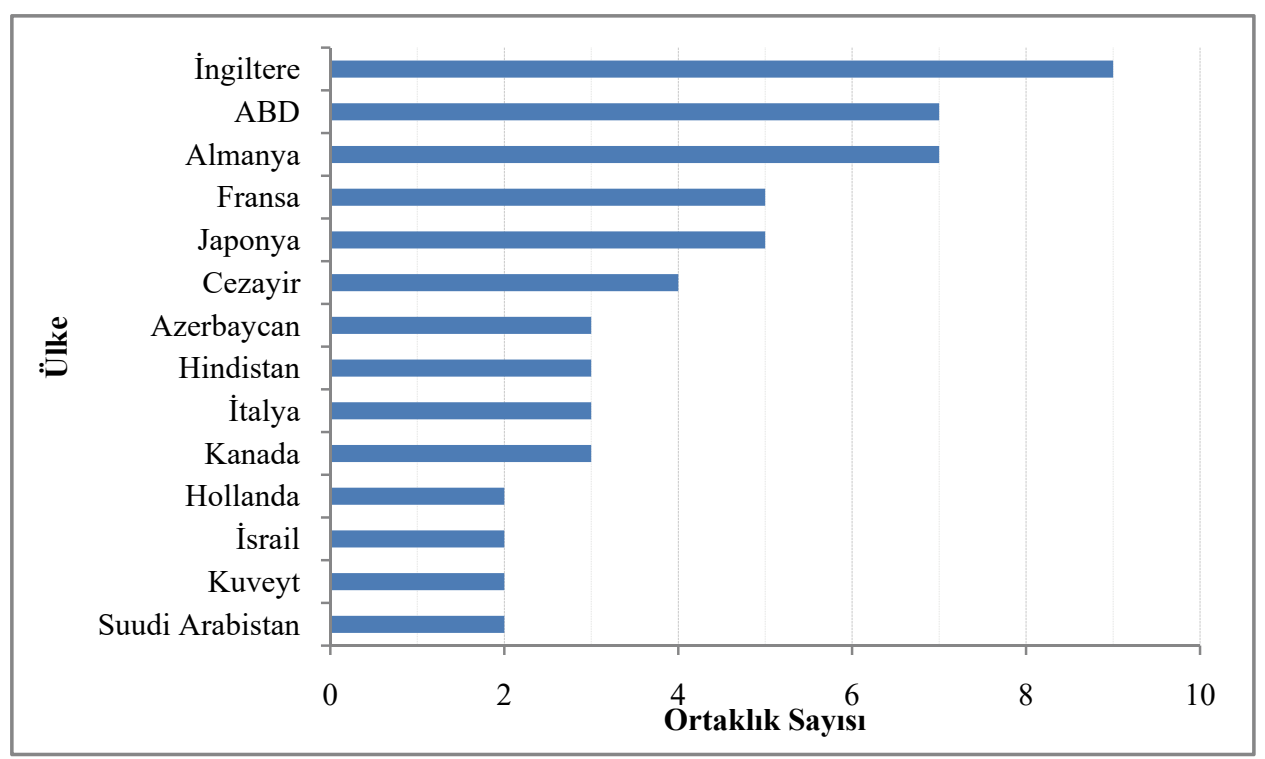

Şekil 1. Ülkelere Göre Ortaklikların Dă̆ılımı 
Uluslararası Ortak Girişimlerin Başarısında Kültürel Uyumun Etkisinin İncelenmesi

Her ülke için ayrı ayrı UOG başarı puanları ve kurumsal kültür ile ulusal kültür uyum değerleri Çizelge 2'de gösterilmiştir. Öznel UOG başarı sırası baz alınarak oluşturulan bu çizelgeye göre, Türk firmalarının genellikle Azerbaycan, Mısır ve Belçika'dan olan ortaklarından daha memnun oldukları gözlenirken Avusturya, Pakistan ve Danimarka'dan olan ortaklarıyla kurdukları UOG performanslarından yeterli derecede memnuniyet duymadıkları gözlemlenmiştir.

Çizelge 2. Ülke Bazında UOG başarısı, Ulusal Kültür ve Kurumsal Kültür Uyumu Değerleri

\begin{tabular}{|c|l|c|ccc|}
\hline No & Ülke & $\begin{array}{c}\text { Ortaklık } \\
\text { Sayısı }\end{array}$ & $\begin{array}{c}\text { Ulusal } \\
\text { Başarısı }\end{array}$ & $\begin{array}{c}\text { Külttür } \\
\text { Uyumu }\end{array}$ & $\begin{array}{c}\text { Külttür } \\
\text { Uyumu }\end{array}$ \\
\hline 1 & Azerbaycan & 3 & 5,000 & 3,944 & 4,494 \\
2 & Misır & 1 & 5,000 & 3,471 & 3,818 \\
3 & Belçika & 1 & 4,000 & 3,000 & 3,870 \\
4 & Fransa & 5 & 4,000 & 2,995 & 3,408 \\
5 & Irak & 1 & 4,000 & 3,000 & 3,522 \\
6 & İsrail & 2 & 4,000 & 2,861 & 2,491 \\
7 & İtalya & 3 & 4,000 & 3,611 & 3,925 \\
8 & Kuveyt & 2 & 4,000 & 2,875 & 3,917 \\
9 & Libya & 1 & 4,000 & 2,357 & 2,833 \\
10 & Rusya & 1 & 4,000 & 3,842 & 3,091 \\
11 & İngiltere & 9 & 3,667 & 2,886 & 3,643 \\
12 & Japonya & 5 & 3,600 & 3,211 & 3,371 \\
13 & Suudi Arabistan & 2 & 3,500 & 3,309 & 3,524 \\
14 & Almanya & 7 & 3,429 & 3,561 & 3,457 \\
15 & ABD & 7 & 3,429 & 2,975 & 3,173 \\
16 & Kanada & 3 & 3,333 & 2,600 & 3,333 \\
17 & Afganistan & 1 & 3,000 & 2,250 & 2,870 \\
18 & BAE & 1 & 3,000 & 3,706 & 2,960 \\
19 & Cezayir & 4 & 3,000 & 3,250 & 2,761 \\
20 & Güney Afrika & 1 & 3,000 & 3,938 & 3,690 \\
21 & Hindistan & 3 & 3,000 & 2,549 & 2,975 \\
22 & Hollanda & 2 & 2,500 & 2,456 & 2,869 \\
23 & Danimarka & 1 & 2,000 & 3,190 & 3,167 \\
24 & Pakistan & 1 & 2,000 & 3,000 & 2,429 \\
25 & Avusturya & 1 & 1,000 & 2,067 & 2,429 \\
\hline
\end{tabular}


Ayrıca, ulusal ve kurumsal kültür uyumu değerlerine göre en yüksek 10 ülkenin gösterildiği ülkeler sıralaması da Şekil 2 ve 3'te gösterilmiştir. Şekil 2, Şekil 3 ve Çizelge 2 beraber değerlendirildiğinde, Türk firmalarının Azeri, İtalyan ve Kuveyt'li firmalara kurumsal kültür açısından daha fazla benzerlik taşıdığı, Avusturya, Pakistan ve İsrail'den olan ortakları ile arasında fazla kültürel mesafe olduğu görülmüştür. Ayrıca, ulusal kültür açısından, Türk firmalarının Azeri, Güney Afrika'lı ve Rus firmalarla benzer özellikler taşıdığı görülürken Avusturya, Afganistan ve Libya'dan olan ortakları ile daha fazla kültürel farklılık taşıdığı görülmüştür. Toplamda 68 projeden elde edilen veriler 1şığında, kurulan UOG'lerin başarı değerleri ortalaması 3,418; ulusal kültür uyum değerleri ortalaması 3,076 ve kurumsal kültür uyum değerleri ortalaması ise 3,281 olarak bulunmuştur.

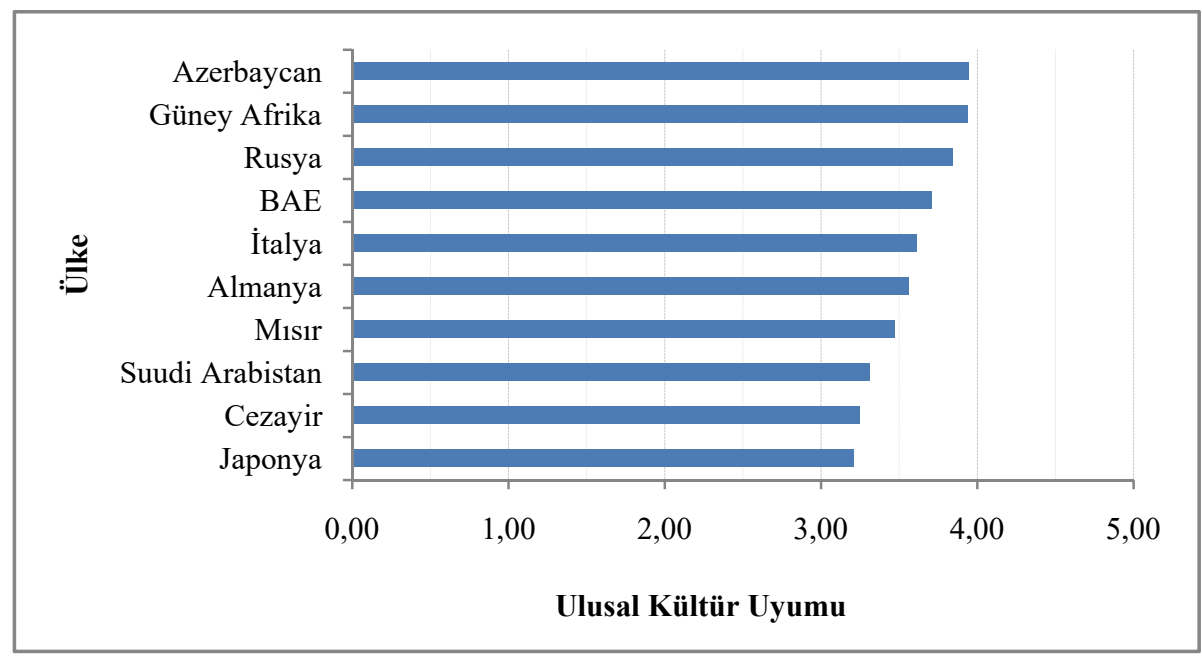

Şekil 2. Ulusal Kültür Uyumu Açısından Ülke Sıralaması

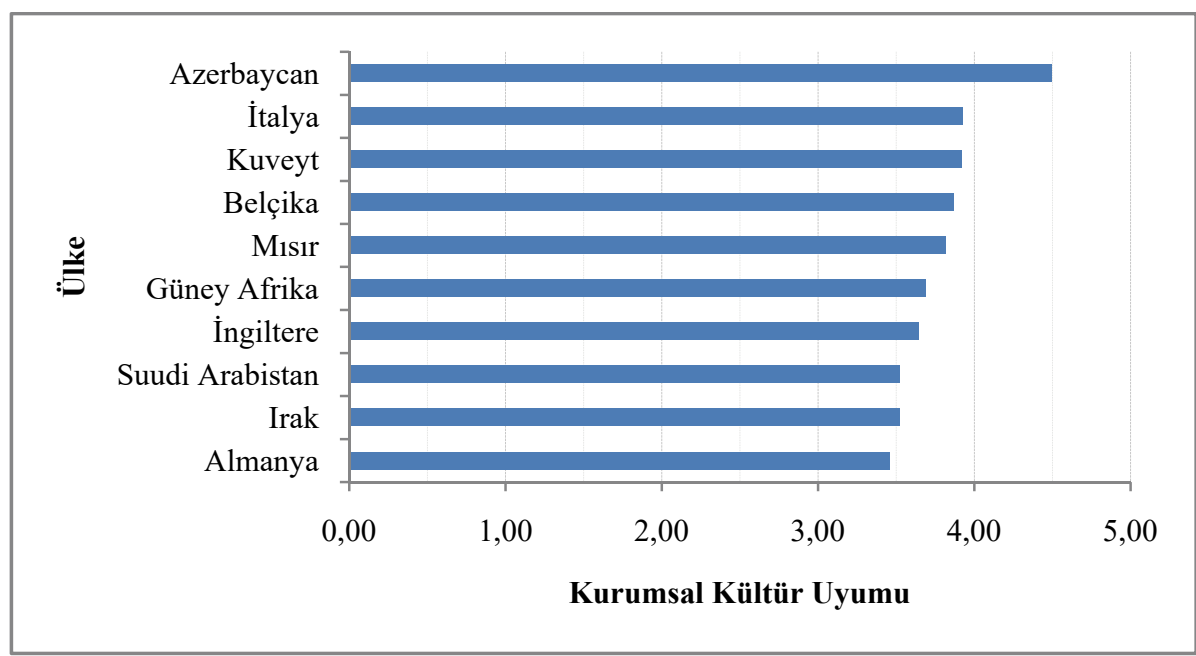

Şekil 3. Kurumsal Kültür Uyumu Açısından Ülke Stralaması 


\section{Uluslararası Ortak Girișimlerin Başarısında Kültürel Uyumun Etkisinin İncelenmesi}

$\mathrm{Bu}$ çalışmada, UOG başarısı bağımlı değişken olarak tanımlanmış ve ulusal kültür ile kurumsal kültür de ayrı bağımsız değişkenler olarak değerlendirilmiştir. Bu değerlendirme sonucunda çok değişkenli bir regresyon analizi gerçekleştirilmiştir. Regresyon analizi sonucunda, regresyonun anlamlılığını ölçen kriterlerden biri olan $\mathrm{R}^{2}$ değeri 0,549 olarak belirlenmişşir (Çizelge 3). $\mathrm{R}^{2}$ değerlendirme kriterine göre, verilerin yaklaşık yüzde 55 ' çalışma kapsamında oluşturulan regresyon modeli ile uyum göstermektedir. Bir başka deyişle, değişkenlerdeki değişmelerin $\% 55$ 'i regresyon doğrusu ile açıklanabilmektedir. Ulusal kültür ve kurumsal kültür uyumu değerlerinin ondalık sayı değerler ve UOG başarısı değerlerinin tamsayı değerler olması nedeniyle veri-model uyumu yüzdesinin daha yüksek olduğu düşünülmektedir.

Çizelge 3 - Regresyon İstatistikleri

\begin{tabular}{lr}
\hline Parametre & Değer \\
\hline Çoklu R & 0,7411 \\
$\mathrm{R}^{2}$ & 0,5493 \\
Ayarlanmış $\mathrm{R}^{2}$ & 0,5354 \\
Standart Hata & 0,5199 \\
Gözlem & 68 \\
\hline
\end{tabular}

Regresyon modelinin uygunluğu tamsayılardan oluşmayan bir ölçek ya da daha büyük aralıklı bir ölçeğin kullanılması durumunda daha fazla veri sayısını temsil edebilmektedir. Regresyon modellerinde ondalıklı değerlerin yuvarlanması, değişken veya bir regresyon çizgisinin varyansını hesaplamak için gerçek değerler yerine kullanıldığında, sonuçlar gerçeği yansıtmamakta ve veri hatalı olarak değerlendirilmektedir. Değişkenlerin dağılımına ilişkin uygun düzgünlük koşullarında bu önyargı ancak "Sheppard'ın düzeltme yöntemi" ile çok yüksek hassasiyetle düzeltilebilmektedir. Schneeweiss ve Komlos [58] asimetrik yuvarlama ve karmaşık yuvarlamayı içeren basit yuvarlama ve olasılıklı yuvarlamadan ziyade, yuvarlama prosedürlerini daha genel hatlariyla kapsayan Sheppard'ın düzeltme yöntemini geliştirerek uygulamışlardır. Bu çalışmada, bu yuvarlama etkisini azaltmak amacıyla, Sheppard'ın düzeltme yaklaşımı Denklem (1) - (3)'te gösterildiği gibi kullanılmış olup, regresyon modeli $\mathrm{R}^{2}$, si 0,636'ya yükselmiştir [59].

$S^{2}=\sqrt{{\overline{(0,519)^{2}}}^{2}-\frac{1^{2}}{12}}=0,187$

$S S_{\text {hata }}=S^{2} \times d f=0,187 \times 65=12,159$

$R^{2}=\frac{S S_{\text {regresson }}}{S S_{\text {toplam }}}=\frac{S S_{\text {toplam }}-S S_{\text {hata }}}{S S_{\text {toplam }}}=\frac{33,4-12,159}{33,4}=\% 63,6$

İki değişkenli regresyon analizi yapılan modelde $\% 55$ gibi yüksek bir temsil oranı mevcut olup, yuvarlamadan oluşan olumsuzluğu ortadan kaldırmak amacıyla Sheppard düzeltme 
yaklaşımı kullanılmıştır. Bu yaklaşım sonucunda, bu gösterge \%64 gibi bir orana yükselmiştir. Ayrıca hem kurumsal kültür $(0,0476)$ hem de ulusal kültür $(0,0001)$ değerleri, anlamlılık düzeyleri 0,05 'ten küçük olduğu için, UOG başarısı üzerinde önemli ölçüde etkilidir (Çizelge 4). Regresyon modeli Denklem (4)'te verilmiştir.

UOG Başarlsı=0,298 +0,254×Ulusal Kültür Uyumu + 0,723 $\times$ Kurumsal Kültür Uyumu

UOG başarısının belirlenmesinde ulusal kültür ve kurumsal kültür uyumu için oluşturulan regresyon modelinin önemini test etmek amacıyla, kurumsal kültür ve ulusal kültürün UOG başarısı ile arasında herhangi bir ilişkinin olmadığı hipotezi varsayılarak (sıfır hipotezi), hipotez testine başvurulmuştur. Çizelge 4'te görüldüğü üzere, anlamlılık düzeyinin 0,05 olarak kabul edildiği testte, ulusal kültür ve kurumsal kültürün $\mathrm{p}$ değerlerinin sırasılyla 0,0476 ve 0,0001 olduğu tespit edilmiştir. Her iki değerin de anlamlılık düzeyi olan 0,05 'ten daha küçük olmaları sebebiyle sıfir hipotezinin reddedilmesi gerektiği öngörülmektedir. Dolayısıyla hem ulusal kültürün hem de kurumsal kültürün bu çalışmada öznel bir bileşen olarak incelenen UOG başarısı üzerinde oldukça etkili olduğu görülmektedir [60].

Korelasyon analizi istatistiki verilerin incelenmesinde sıklikla kullanılan istatistiksel yöntemlerden biri olmuştur. Literatürde, korelasyon katsayısını kategorize eden etiketleme sistemlerine göre, genellikle mutlak değeri 0,35 'in altındaki korelasyonlar düşük ya da zayıf korelasyon olarak kabul edilirken, (mutlak değer olarak) korelasyon katsayıları, 0,36 ile 0,67 arasındaki korelasyonlar için mütevazı veya orta korelasyon, değerleri 0,68 ile 1,0 arasında olan korelasyon katsayıları için güçlü veya yüksek korelasyon ve korelasyonları 0,90'dan büyük olan modeller için ise çok yüksek korelasyon kabulleri yapılmaktadır [61]. İki değişkenin (kurumsal kültür ve ulusal kültür) ölçeklerinden bağımsız olarak yorumlanabilmesi ve sınırlı bir ölçüm elde etmek için, korelasyon katsayıları tespit edilmiş ve bu katsayılar Çizelge 4'de gösterilmiştir. Korelasyon katsayıları incelendiğinde, kurumsal kültür ve UOG başarısı arasında güçlü bir ilişki olduğu görülmesine rağmen, ulusal kültür ve UOG başarısı arasında orta düzeyde bir ilişki olduğu gözlenmektedir.

Analiz sonuçları incelendiğinde, kurumsal kültür ile UOG başarısı arasında çok güçlü bir ilişkinin söz konusu olduğu fakat ulusal kültürün UOG başarısı üzerindeki etkisinin oldukça düşük olduğu görülmüştür. Ayrıca, kurumsal kültürün UOG başarısı üzerindeki etkisi diğer çalışmalar tarafindan da desteklenmektedir [53].

Çizelge 4 - Değişkenler arası korelasyonlar

\begin{tabular}{lcccc}
\hline & $\begin{array}{c}\text { UOG } \\
\text { Başarısı }\end{array}$ & $\begin{array}{c}\text { Ulusal Külttür } \\
\text { Uyumu }\end{array}$ & $\begin{array}{c}\text { Kurumsal } \\
\text { Kültür Uyumu }\end{array}$ & p-değeri \\
\hline UOG Başarısı & 1,000 & & & \\
Ulusal Kültür & 0,453 & 1,000 & & 0,0476 \\
Kurumsal Kültür & 0,722 & 0,415 & 1,000 & 0,0001 \\
\hline
\end{tabular}


Uluslararası Ortak Girişimlerin Başarısında Kültürel Uyumun Etkisinin İncelenmesi

\section{SONUÇLAR}

Küresel rekabette artan stratejik önemleri nedeniyle, UOG'ler araştırmacıların yoğun ilgisini çekmektedir. Geçtiğimiz yıllarda uluslararası iş dünyasında görülen en büyük değişikliklerden biri olan artan UOG faaliyetleri çok uluslu şirketler için sık başvurulan bir yöntem olmuştur. Günümüzde, bu tür girişimlere başvurma sayısındaki artış, UOG'lerin coğrafi kapsamları ile uluslararası ve kültürlerarası değişkenleri barındırmaları nedeni ile değişiklik göstermektedir. Araştırmalar sonucunda en dikkat çekici unsur ise, OG çalışmalarının çoğunluğunun kültür konusu üzerinde yoğunlaşmasıdır.

$\mathrm{Bu}$ çalışma kapsamında ulusal ve kurumsal kültürel uyumun Türk firmalarının çeşitli ülkelerden ortaklarıyla oluşturdukları UOG'lerin performansı üzerindeki etkisini incelemek amaçlanmıştır. Bu amaçla bir anket çalışması gerçekleştirilmiş ve bu anket TMB üyesi olan orta ve büyük ölçekli müteahhit firmalara uygulanmıştır. Anket verileri ışığında yapılan regresyon ve korelasyon analizleriyle, Türk firmalar ve yabancı ortakları arasındaki kültürel uyum ölçülmüş ve kültürel uyum ile UOG performansı arasındaki ilişki de araştırılmıştır. $\mathrm{Bu}$ çalışmanın bulgularına göre, Türk firmalarının kurumsal kültür açısından Azeri, İtalyan ve Kuveytli ortaklarla daha benzer; Avusturya, Pakistan ve İsrailli ortaklarla daha farklı özellikler taşıdığı görülmüştür. Ulusal kültür açısından bakıldığında ise, Türk firmaların daha çok Azeri, Güney Afrika'lı ve Rus firmalarıyla benzer özellikler sergilediği fakat Avusturya'lı, Afgan ve Libya'lı firmalarla ise daha farklı özellikler gösterdiği gözlenmiştir. Aynı zamanda hem ulusal hem kurumsal kültür açısından ortaklar arası uyumun UOG performansını olumlu etkilediği gözlemlenmiş ve kurumsal kültürün UOG başarısı üzerinde ulusal kültürden daha etkin bir faktör olduğu belirlenmiş̧ir. Çalışma neticesinde, benzer kültürlere sahip ortakların UOG faaliyetlerini daha etkin bir şekilde yürütme şansına sahip oldukları sonucu çıkarılabilmektedir. Ayrıca, gelecek çalışmalar açısından, UOG'lerin benimsenmesi ve başarılı bir şekilde yönetilmesinin önündeki engellerin belirlenmesi ve uygulamadaki UOG müteahhitlik stratejilerinin uygunluğu ve etkinliğinin araştırılması önerilmektedir.

\section{Kaynaklar}

[1] Porter M. E., The competitive advantage of nations. New York, Free Press, 1990.

[2] Geringer, J. M., Joint venture partner selection: Strategies for developing countries, Quorum, New York., 1988.

[3] Makino, S., Beamish, P. W., Performance and survival of international joint ventures with non-conventional ownership structures. J. Int. Business Stud., 29(4), 797-818, 1998.

[4] Parkhe, A., "Messy" research, methodological predispositions, and theory development in international joint ventures. Academy of Management Review, 18(2), 227-268, 1993.

[5] Robson, M. J., Leonidou, L. C., Katsikeas, C. S., Factors Influencing International Joint Venture Performance: Theoretical Perspectives, Assessment, and Future Directions Management International Review, 42(4), 385-418, 2002. 
[6] Bing, L., Tiong, R. L. K., Risk management model for international construction joint ventures. J. Constr. Eng. Manage., 125(5), 377-384, 1999.

[7] Bing, L., Tiong, R. L. K., Fan, W. W.,Chew, D. A. S,.Risk management in international construction joint ventures. J. Constr. Eng. Manage., 125(4), 277-284, 1999.

[8] Mohamed, S., Performance in international construction joint ventures: Modeling perspective. J. Constr. Eng. Manage., 129(6), 619-626, 2003.

[9] Gale, A., Luo, J., Factors affecting construction joint ventures in China. Int. J. Proj. Manage., 22(1), 33-42, 2004.

[10] Chan, E. H. W., Tse, R. Y. C., Cultural considerations in international construction contracts. Journal of Construction Engineering and Management, 129, 375-381, 2003.

[11] Ozorhon, B., Arditi, D., Dikmen, I., Birgonul, M. T., The performance of international joint ventures in construction. ASCE Journal of Management in Engineering, 26, 209$222,2010$.

[12] Larimo, J. A., Nguyen, H. L., International joint venture strategies and performance in the Baltic States. Baltic Journal of Management, 10(1), 52-72, 2015.

[13] Gollnhofer, J. F., Turkina, E., Cultural distance and entry modes: implications for global expansion strategy. Cross Cultural Management, 22(1), 21-41, 2015.

[14] Kagioglou, M., Cooper, R., Aouad, G., Performance management in construction: A conceptual framework. Constr. Manage. Econom., 19, 85-95, 2001.

[15] Chan, A. P. C., Chan, D. W. M., Chiang, Y. H., Tang, B. S., Chan, E. H. W., Ho, K. S. K., Exploring critical success factors for partnering in construction projects. J. Constr. Eng. Manage., 130(2), 188-198, 2004.

[16] Ozorhon, B., Arditi, D., Dikmen, I., Birgonul, M. T., Implications of culture in the performance of international construction joint ventures. Journal of Construction Engineering and Management. 134, 361-370, 2008.

[17] Abdul-Rahman, H., Wang, C., Wood, L. C., Ismail, S., International joint venture between Asean and Gulf: Bidding and delivering Bahrain international Formula-1 circuit. A Journal of the Humanities and Social Sciences, 18(4), 357-382, 2014.

[18] Kogut, B., Singh, H., The effect of national culture on the choice of entry mode. Journal of International Business Studies, 19, 411-432, 1988.

[19] Park, S. H., Ungson, G. R., The effect of national culture, organizational complementarity, and economic motivation on joint venture dissolution. Academy of Management Journal, 40, 279-307, 1997.

[20] O’Grady, S., Lane, H. W., The psychic distance paradox. J. Int. Business Stud., 27(2), 309-333, 1996.

[21] Mead, R., International management. Oxford, Blackwell, 2nd Ed., 1998. 
Uluslararası Ortak Girişimlerin Başarısında Kültürel Uyumun Etkisinin İncelenmesi

[22] Hofstede, G., Hofstede, G. J., Cultures and organizations:Software of the mind, 2nd Ed., New York, McGraw-Hill, 2005.

[23] Evans, J., Treadgold, A., Mavondo, F., Explaining export development through psychic distance. International Marketing Review 17(2), 164-168, 2000.

[24] Hofstede, G., Culture's consequences: International differences in work-related values, Beverly Hills, California, Sage, 1980.

[25] Hofstede, G., Cultures and organizations: Software of the mind, intercultural cooperation and its importance for survival, McGrawHill, New York, 1991.

[26] Demirbag, M., Mirza, H., Factors affecting international joint venture success: An empirical analysis of foreign-local partner relationships and performance in joint ventures in Turkey. Int. Bus. Rev., 9(1), 1-35, 2000.

[27] Janger, A. R., Organization of international joint ventures. New York: The Conference Board, 1980.

[28] Killing, P. J., Strategies for joint venture success. London. Croom Helm, 1983.

[29] Tatoglu, E., Glaister, K. W., Performance of international joint ventures in Turkey: Perspectives of Western firms and Turkish firms. International Business Review, 7, 635-656, 1998.

[30] Morris, D., Hergert, M., Trends in international collaborative agreements. Columbia Journal of World Business, 23(2), 15-21, 1987.

[31] Harrigan, K. R., Joint ventures and competitive strategy. Strategic Management Journal, 9(2), 141-158, 1988.

[32] Parkhe, A., Interfirm diversity, organizational learning, and longevity in global strategic alliances. Journal of International Business Studies, Fourth Quarter, 579601, 1991.

[33] Beamish, P. W, Multinational joint ventures in developing countries, London, Routledge, 1988

[34] Luo, Y., Joint venture success in China: How should we select a good partner? J. World Bus., 33(2), 145-166, 1998.

[35] Inkpen, A. C., Currall, S. C., The nature, antecedents, and consequences of joint venture trust. J. Int. Manag., 4(1), 1-20, 1998.

[36] Mohr, J., Spekman, R., Characteristics of partnership success: partnership attributes, communication behaviour, and conflict resolution techniques. Strategic Management Journal, 15(2), 135-152, 1994.

[37] Hennart, J. F., Kim, D. J., Zeng, M., The impact of joint venture status on the longevity of Japanese stakes in U.S. manufacturing affiliates. Org. Sci., 9(3), 382395, 1998. 
[38] Johanson, J., Vahlne, J. E., The internationalization process of the firm-a model of knowledge development and increasing foreign market commitments. J. Int. Business Stud., 8(1), 23-32, 1977.

[39] Luo, Y., Partner selection and venturing success: The case of joint ventures with firms in the People's Republic of China. Org. Sci., 8(6), 648-662, 1997.

[40] Gunhan, S., Arditi, A., Factors affecting international construction. J. Constr. Eng. Manage., 131(3), 273-282, 2005.

[41] Beamish, P.W., Joint venture performance in developing countries. Unpublished doctoral dissertation, University of Western Ontario, 1984.

[42] Sridharan, G., Factors affecting the performance of international joint ventures-A research model. Proc., 1st Int. Conf. on Construction Industry Development, National Univ. of Singapore, Singapore, 2, 84-91, 1997.

[43] Cartwright, S., Cooper, C. L., The role of culture compatibility in successful organizational marriage. Acad. Manage. Exec., 7(2), 57-70, 1993.

[44] Barkema, H. G. Vermeulen, F., What differences in the cultural backgrounds of partners are detrimental for international joint ventures? Journal of International Business Studies, 28, 845-864, 1997.

[45] Brouthers, K., Brouthers, L., Explaining the national cultural distance paradox. J. Int. Business Stud.,32(1), 177-189, 2001.

[46] Sim, A. B., Ali, M. Y., Determinants of stability in international joint ventures: Evidence from a developing country context. Asia Pac. J. Manage., 17(3), 373-397, 2000.

[47] Nielsen, B. B., Determining international strategic alliance performance. Working Paper-6, Copenhagen Business School Department of International Economics and Management, Copenhagen, Denmark, 2002.

[48] Fey, C. F., Beamish, P. W., The importance of organizational climate similarity between parent firms and the JV: The case of IJVs in Russia. Organization Studies, 22, 853-882, 2001.

[49] Tihanyi, L., Griffith, D. A., Russell, C. J., The effect of cultural distance on entry mode choice, international diversification. and MNE performance: A meta-analysis. J. Int. Bus. Stud., 36(3), 270-283, 2005.

[50] Schein, E., Organizational culture and leadership, 2nd Ed., San Francisco, JosseyBass, 1992.

[51] Erez, M., Gati, E., A dynamic, multi-level model of culture: From the micro level of the individual to the macro level of a global culture. Applied Psychology: An International Review, 53(4), 583-598, 2004.

[52] Hofstede, G., Neuijen, B., Ohayv, D., Sanders, G., Measuring organizational cultures: A qualitative and quantitative study across twenty cases. Administrative Science Quarterly, 35, 286-316, 1990. 
Uluslararası Ortak Girişimlerin Başarısında Kültürel Uyumun Etkisinin İncelenmesi

[53] Pothukuchi, V., Damanpour, F., Choi, J., Chen, C.C., Park, S. H., National and organizational culture differences and international joint venture performance. Journal of International Business Studies, 33, 243-265, 2002.

[54] Brown L. T., Rugman A. M., Verbeke A., Japanese joint ventures with Western multinationals: Synthesizing the economic and cultural explanations of failure. Asia Pacific Journal of Management, 6(2), 225-242, 1989.

[55] Hofstede, G., Identifying organizational subcultures: An empirical approach. J. Manage. Stud. (Oxford), 35(1), 1-12, 1998.

[56] Kogut, B., Joint ventures: Theoretical and empirical perspectives. Strategic Manage. J., 9(4), 319-332, 1988.

[57] Contractor, F. J. Lorange, P,. Why should firms cooperate? The strategy and economics basis for cooperative ventures. Cooperative strategies in international business, F. J. Contractor and P. Lorange, eds., Lexington books, Lexington, Mass, 1988.

[58] Schneeweiss, H., Komlos, J., Probabilistic Rounding and Sheppard's Correction. Technical Report Number 045, Department of Statistics University of Munich, Munich, 2008.

[59] Wold, H., Sheppard's correction formulae in several variables. Scandinavian Actuarial Journal, 1934(1), 1934.

[60] Yue, S., Pilon, P., Cavadias, G., Power of the Mann-Kendall and Spearman's rho tests for detecting monotonic trends in hydrological series. Journal of Hydrology, 264(14), 262-263, 2002.

[61] Taylor, R., Interpretation of the Correlation Coefficient: A Basic Review. Journal of Diagnostic Medical Sonofgraphy, 6, 35-39, 1990. 